九州大学学術情報リポジトリ

Kyushu University Institutional Repository

ニボルマブを投与した再発または遠隔転移を有する 頭頸部扁平上皮癌症例の, 兔疫関連有害事象と長期 的予後との関係

松尾，美央子

http://hdl. hand le. net/2324/4474895

出版情報：Kyushu University，2020，博士（医学），論文博士 バージョン：

権利関係: (c) 2019 Elsevier Ltd. All rights reserved. 


\title{
Relationship between immune-related adverse events and the long-term outcomes in recurrent/metastatic head and neck squamous cell carcinoma treated with nivolumab
}

\author{
Mioko Matsuo $^{\mathrm{a}}$, Ryuji Yasumatsu ${ }^{\mathrm{a}, *}$, Muneyuki Masuda $^{\mathrm{b}}$, Satoshi Toh ${ }^{\mathrm{b}}$, Takahiro Wakasaki ${ }^{\mathrm{a}}$, \\ Kazuki Hashimoto ${ }^{a}$, Masahiko Taura ${ }^{a}$, Ryutaro Uchi ${ }^{a}$, Takashi Nakagawa ${ }^{a}$ \\ ${ }^{a}$ Department of Otorhinolaryngology, Graduate School of Medical Sciences, Kyushu University, Fukuoka 812-8582, Japan \\ ${ }^{\mathrm{b}}$ Department of Head and Neck Surgery, National Hospital Organization Kyushu Cancer Center, Fukuoka 811-1395, Japan
}

\section{A R T I C L E I N F O}

\section{Keywords:}

Head and neck squamous cell carcinoma Nivolumab

Immune-related adverse events

\begin{abstract}
A B S T R A C T
Objectives: Immune-related adverse events (irAEs) have been shown to be associated with higher antitumor responses and a clinical benefit in non-small cell lung carcinoma, renal cell carcinoma, and melanoma patients. However, little is known regarding the association between irAEs and the clinical effect of nivolumab for recurrent/metastatic head and neck squamous cell carcinoma (R/MHNSCC).

Materials and methods: We evaluated 108 patients treated with nivolumab for R/MHNSCC at 2 participating institutions. IrAEs were identified and profiled. We analyzed the association of each immune-related adverse effect with the clinical outcome of the patients.

Results: Among 108 patients, the objective response rate (ORR) was 29.6\% (32/108 patients), and the disease control rate (DCR) was 50.0\% (54/108 patients). IrAEs were observed in 41 patients (38.0\%). Patients with irAEs had a significantly higher ORR and DCR than those without irAEs (46.3\% vs. 19.4\%, P = 0.004 and $75.6 \%$ vs. $34.3 \%, \mathrm{P}<0.001$, respectively). The median progression-free and overall survival rates in patients with irAEs were significantly longer than in those without irAEs.

Conclusions: There was a significant relationship between irAEs and efficacy in R/MHNSCC patients treated with nivolumab. Our results indicate that the development of irAEs may aid in the earlier prediction of anticancer effects in patients with recurrent or metastatic HNSCC during nivolumab monotherapy.
\end{abstract}

\section{Introduction}

Nivolumab, an anti-programmed death-1 (PD-1) antibody, is an immune checkpoint inhibitor (ICI), which are new cancer immunotherapy agents. The recent CheckMate 141 clinical trial reported that nivolumab was effective in extending the median overall survival (OS) in this patient population compared with standard chemotherapies. Based on these data, nivolumab has been approved for the treatment of patients with R/MHNSCC who demonstrate disease progression either during or after receiving platinum-based therapy [1]. The unique point of ICIs is that these drugs offer a clinical benefit even if they seem to be ineffective [2], and some patients show a persistent long-term effect even after stopping nivolumab therapy [3].
However, in some cases, ICIs have induced side effects known as "immune-related adverse events (irAEs)", which differ from the effects experienced with traditional chemotherapy and targeted therapy [4]. Recent reports have suggested that the occurrence of irAEs was related to higher antitumor responses and a clinical benefit in patients with non-small-cell lung carcinoma [5,6], melanoma [7], and renal cell carcinoma [8]. In addition, several previous reports have suggested that a better outcome after treatment with ICIs was associated with multiple irAEs [5], severe irAEs (grade $\geq 3$ ) [9], the location of the manifested irAE (e.g. cutaneous irAEs) $[7,8,10]$, and an early irAE onset (within two weeks of administration) [11].

The present study evaluated the association between the irAE profile and nivolumab efficacy in patients with R/MHNSCC.

\footnotetext{
* Corresponding author at: Department of Otorhinolaryngology, Graduate School of Medical Sciences, Kyushu University, 3-1-1 Maidashi, Higashi-ku, Fukuoka 812-8582, Japan.

E-mail address: yasuryuj@qent.med.kyushu-u.ac.jp (R. Yasumatsu).
} 


\section{Materials and Methods}

Patients

From April 2017 to August 2018, 108 patients with R/MHNSCC who were treated with nivolumab were retrospectively analyzed. The clinical characteristics of the patients are summarized in Table 1.

All tumors were histologically confirmed to be SCC. The Eastern Cooperative Oncology Group (ECOG) performance status was 0 in 52 patients, PS 1 in 49 patients, PS 2 in 5 patients and PS 3 in 2 patients. Nivolumab was used as a first-line therapy in $59.2 \%$ (64/108 patients), a second-line therapy in $30.6 \%$ (33/108 patients), a third-line therapy in $9.3 \%(10 / 108$ patients) and a fourth-line therapy in $0.9 \%(1 / 108$ patients).

Patient follow-up lasted until death or until the cut-off date (June 30 , 2019). The median follow-up interval was 7.5 months (range 0.3-27 months).

\section{The evaluation of the response}

The tumor response was evaluated using the Response Evaluation Criteria in Solid Tumors (version1.1) based on the findings of computed tomography which was performed every 8 to 12 weeks. Progressive disease (PD) was defined as a $\geq 20 \%$ increase in the sum of the diameters of the target lesions or the appearance of new metastatic lesions. Stable disease (SD) was defined as ranging from a $<30 \%$ decrease to a

Table 1

The patients characteristics according to the development of immune-related adverse events (irAEs).

\begin{tabular}{|c|c|c|c|c|}
\hline \multirow[t]{2}{*}{ Characteristics } & \multicolumn{3}{|c|}{ Number of patients (\%) } & \multirow[t]{2}{*}{$P$ value } \\
\hline & $\begin{array}{l}\text { Total } \\
(\mathrm{n}=108)\end{array}$ & $\begin{array}{l}\text { With irAEs } \\
(\mathrm{n}=41)\end{array}$ & $\begin{array}{l}\text { Without } \\
\text { irAEs } \\
(n=67)\end{array}$ & \\
\hline \multicolumn{5}{|l|}{ Age } \\
\hline$<75$ years & $90(83.3)$ & $36(87.8)$ & $54(80.6)$ & 0.380 \\
\hline$\geqq 75$ years & $18(16.7)$ & $5(12.2)$ & $13(19.4)$ & \\
\hline Median (range) & $66.0(24-87)$ & $\begin{array}{l}64.0 \\
(33-84)\end{array}$ & $67.0(24-87)$ & 0.127 \\
\hline Gender & & & & 0.021 \\
\hline Male & $81(75.0)$ & $36(87.8)$ & $45(67.2)$ & \\
\hline Female & $27(25.0)$ & $5(12.2)$ & $22(37.8)$ & \\
\hline ECOG PS & & & & 0.249 \\
\hline $0-1$ & 101(93.5) & $40(97.6)$ & $61(91.0)$ & \\
\hline $2-4$ & $7(6.5)$ & $1(2.4)$ & $6(9.0)$ & \\
\hline Primary site & & & & 0.050 \\
\hline Sinonasal truct & $16(14.8)$ & $9(22.0)$ & $7(10.4)$ & \\
\hline Oral cavity & $28(25.9)$ & $6(14.6)$ & $22(32.9)$ & \\
\hline Nasopharynx & $6(5.6)$ & $2(4.9)$ & $4(6.0)$ & \\
\hline Oropharynx & $19(17.6)$ & $9(22.0)$ & $10(14.9)$ & \\
\hline Hypopharynx & $26(24.1)$ & $13(31.6)$ & $13(19.3)$ & \\
\hline Larynx & $5(4.6)$ & $2(4.9)$ & $3(4.5)$ & \\
\hline $\begin{array}{l}\text { External auditory } \\
\text { canal }\end{array}$ & $6(5.6)$ & $0(0.0)$. & $6(9.0)$ & \\
\hline $\begin{array}{l}\text { Others (salivary gland } \\
\text { \& primary unknown) }\end{array}$ & $2(2.8)$ & $0(0.0)$ & $2(3.0)$ & \\
\hline \multicolumn{5}{|l|}{ PDL-1 expression } \\
\hline+ & $29(26.9)$ & $9(22.0)$ & 20 (29.9) & $0.245^{*}$ \\
\hline- & $9(8.3)$ & $5(12.2)$ & $4(6.0)$ & \\
\hline Not Evaluated & $70(64.8)$ & $27(65.8)$ & $43(64.1)$ & \\
\hline RT to locoregional site & & & & 0.287 \\
\hline Radiotherapy + & $105(97.2)$ & $41(100.0)$ & $64(95.5)$ & \\
\hline Radiotherapy - & $3(2.8)$ & $0(0)$ & $3(4.5)$ & \\
\hline Prior systemic therapy & & & & 0.844 \\
\hline $\begin{array}{l}\text { Cetuximab containing } \\
\text { therapy }+\end{array}$ & $48(44.4)$ & $19(46.3)$ & $29(43.3)$ & \\
\hline $\begin{array}{l}\text { Cetuximab containing } \\
\text { therapy - }\end{array}$ & $60(55.6)$ & $22(53.7)$ & $38(56.7)$ & \\
\hline
\end{tabular}

RT: Radiotherapy.

* Test with the exception of "not evaluated".
$20 \%$ increase in the tumor size on imaging. A partial response (PR) was defined as $\mathrm{a} \geq 30 \%$ decrease in the sum of the diameters of target lesions. We evaluated the best overall response (BOR) of all patients as complete response (CR), $\mathrm{PR}, \mathrm{SD}$ or $\mathrm{PD}$. The objective response rate (ORR) corresponded to CR and PR, and the disease control rate (DCR) corresponded to CR, PR and SD. From the first day of treatment with nivolumab as the starting point, the overall survival (OS) was assessed up until death, and the progression-free survival (PFS) was assessed to the day of disease progression or death. The IrAEs were evaluated according to a protocol described in a previous study [4]. Toxicity was assessed by the Common Terminology Criteria for Adverse Events (CTCAE) version 4.0.

The study protocol was approved by the institutional review board of Kyushu University (reference number: 2019-239) and the Kyushu Cancer Center (reference number: 2019-58). All patients provided their informed consent for the study. This study was conducted in accordance with the principles of the Declaration of Helsinki.

Statistical analyses

All calculations were performed using the JMP 14 software program (SAS Institute, Cary, NC, USA). The OS and PFS were calculated using the Kaplan-Meier method and were evaluated with the log-rank test, and the categorical variables were analyzed using Fisher's exact test. Continuous variables were analyzed using the Mann-Whitney $U$ test. The risk was expressed as hazard ratios (HRs) and 95\% confidence intervals (CIs). Univariate and multivariate Cox proportional hazards regression models were used to assess the associations between potential confounding variables and the PFS and OS. A multivariable analysis was performed after adjusting for age, gender, and PS. Differences with a $\mathrm{p}$ value $<0.05$ considered to be significant.

\section{Results}

\section{Treatment efficacy}

Among all patients, the ORR was $29.6 \%$ (32/108 patients), and the DCR was $50.0 \%$ (54/108 patients). The median OS for all patients was 13.0 months, and the median PFS was 3.7 months. The estimated 1-year OS and PFS rates were $54.4 \%$ and $24.4 \%$, respectively (Fig. 1a, 1b).

\section{IrAE profile}

Forty-one cases (38\%) experienced a total of 53 irAEs. The development of irAEs was more frequent in male patients than in female patients. However, other patient characteristics, including the age, PS, primary site, history of radiotherapy and history of cetuximab-containing therapy, were not significantly associated with irAE emergence (Table 1).

Table 2 summarizes the profiles of the 53 irAEs. The median time from the first day of nivolumab treatment to irAE onset was 8.6 weeks (range 0.1-50). The most typical pattern of irAEs was Grade 1 to 2 (42/ 53 events, $79.2 \%$ ) and an onset after more than 2 weeks (40/53 events, 75.5\%). Regarding the type of irAEs, endocrine irAEs were the most frequent (14/53 events, 26.4\%), followed by skin AEs (11/53 events, $20.8 \%)$ and gastrointestinal AEs (8/53 events, 15.1\%). The median time to the onset of irAEs and the distribution over time of individual irAEs are shown in Fig. 2.

\section{Clinical outcomes and the association of irAEs with nivolumab efficacy}

The patients with irAEs had a significantly higher ORR and DCR than those without irAEs ( $46.3 \%$ vs. $19.4 \%, P=0.004$ and $75.6 \%$ vs. $34.3 \%, P<0.001$ respectively) (Table 3). All five cases with CR had irAEs. The patients with irAEs had a significantly longer median OS and PFS than those without irAEs (not reached (NR) [95\% CI: NR-NR] vs. 
(a)

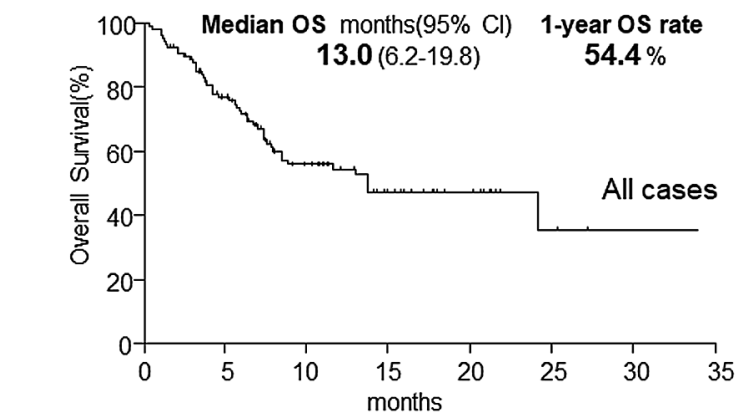

Number at risk

$\begin{array}{llllllll}108 & 75 & 43 & 25 & 11 & 3 & 1 & 0\end{array}$ (b)

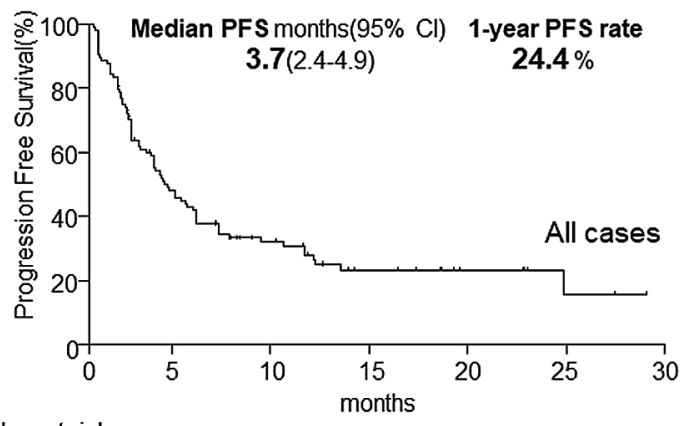

Number at risk

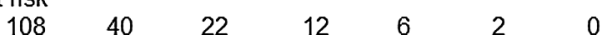

Fig. 1. Kaplan-Meier curves for the (a) overall survival and (b) progression-free survival in all patients.

Table 2

Profiles of irAEs.

\begin{tabular}{|c|c|c|c|c|c|}
\hline \multirow[t]{2}{*}{ Category } & \multicolumn{5}{|c|}{ Number of events (\%) } \\
\hline & Total & $\begin{array}{l}\text { Grade } \\
(1)(2)\end{array}$ & $\begin{array}{l}\text { Grade } \\
(3)(4)\end{array}$ & $\begin{array}{l}\text { Early } \\
(\leqq 2 w)\end{array}$ & $\begin{array}{l}\text { Later } \\
(>2 w)\end{array}$ \\
\hline Any & 53 & $\begin{array}{l}42 \\
(79.2)\end{array}$ & $\begin{array}{l}11 \\
(20.8)\end{array}$ & $\begin{array}{l}13 \\
(24.5)\end{array}$ & $\begin{array}{l}40 \\
(75.5)\end{array}$ \\
\hline Endocrine & $14(26.4)$ & $\begin{array}{l}12 \\
(22.6)\end{array}$ & $2(3.8)$ & 0 & $\begin{array}{l}14 \\
(26.4)\end{array}$ \\
\hline Hypothyroidism & 12 & 12 & 0 & & 12 \\
\hline Hypophysis & 1 & 0 & 1 & & 1 \\
\hline Hyperglycemia & 1 & 0 & 1 & & 1 \\
\hline Skin & $11(20.8)$ & $\begin{array}{l}10 \\
(18.9)\end{array}$ & $1(1.9)$ & $2(3.8)$ & $9(17.0)$ \\
\hline Rash/Pruritus & 11 & 10 & 1 & 2 & 9 \\
\hline Gastrointestinal & $8(15.1)$ & $8(15.1)$ & $0(0.0)$ & $1(1.9)$ & $7(13.1)$ \\
\hline Diarrhea/Nausea & 8 & 8 & 0 & 1 & 7 \\
\hline Hepatobiliary & $6(11.4)$ & $3(5.7)$ & $3(5.7)$ & $4(7.6)$ & $2(3.8)$ \\
\hline $\begin{array}{l}\text { Elevated hepatic } \\
\text { enzymes }\end{array}$ & 5 & 2 & 3 & 3 & 2 \\
\hline Cholangitis & 1 & 1 & 0 & 1 & 0 \\
\hline Pulmonary & $4(7.6)$ & $2(3.8)$ & $2(3.8)$ & $1(1.9)$ & $3(5.7)$ \\
\hline Interstitial pneumonia & 4 & 2 & 2 & 1 & 3 \\
\hline Renal & $4(7.6)$ & $4(7.6)$ & $0(0.0)$ & $2(3.8)$ & $2(3.8)$ \\
\hline Elevated creatinine & 4 & 4 & 0 & 2 & 2 \\
\hline Other & $6(11.4)$ & $3(5.7)$ & $3(5.7)$ & $3(5.7)$ & $3(5.7)$ \\
\hline Myositis/arthritis & 2 & 1 & 1 & 2 & 0 \\
\hline Myocarditis & 1 & 0 & 1 & 0 & 1 \\
\hline Encephalitis & 1 & 0 & 1 & 0 & 1 \\
\hline Ophthalmoneuritis & 1 & 1 & 0 & 0 & 1 \\
\hline Fever & 1 & 1 & 0 & 1 & 0 \\
\hline
\end{tabular}

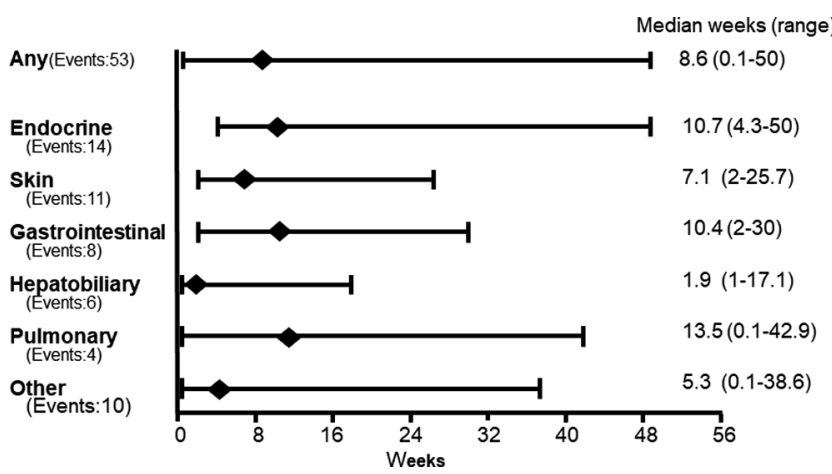

Fig. 2. Time to onset of immune-related adverse events (median with range)
Table 3

The bBest overall response according to the status of with or without irAE

\begin{tabular}{|c|c|c|c|c|}
\hline & \multicolumn{3}{|c|}{ Number of patients (\%) } & \multirow[t]{2}{*}{$P$ value } \\
\hline & $\begin{array}{l}\text { Total } \\
(\mathrm{n}=108)\end{array}$ & $\begin{array}{l}\text { With irAEs } \\
(\mathrm{n}=41)\end{array}$ & $\begin{array}{l}\text { Without irAEs } \\
(\mathrm{n}=67)\end{array}$ & \\
\hline ORR, n(\%) & $32(29.6)$ & $19(46.3)$ & $13(19.4)$ & 0.004 \\
\hline DCR, n(\%) & $54(50.0)$ & 31 (75.6) & $23(34.3)$ & $<0.001$ \\
\hline
\end{tabular}

7.2 months [95\% CI: 6.2-8.7], $P<0.0001$ and 8.0 months [95\% CI: $2.8-13.2$ ] vs. 3.0 months [95\% CI: $1.8-4.2$ ], $P=0.008$, respectively) (Fig. 3a,3b).

The results of univariate and multivariate analyses regarding the prognostic factors influencing the 1-year OS and PFS or median OS and PFS among R/MHNSCC patients are summarized in Table 4. As described above, according to a multivariate analysis, the occurrence of irAEs and PS 0-1 status were independent prognostic factors (HR: 0.29 [95\% CI: 0.13-0.61], $P=0.0007$ and HR: 11.57 [95\% CI: 3.77-33.09], $P<0.0001$ ) of R/MHNSCC patients with nivolumab therapy.

Association between the type of irAEs and clinical outcomes

The PFS according to the number of irAEs ( $\geq 2$ vs. 1 ), severity of irAEs (Grade $\geq 3$ vs. $<3$ ) and the onset of irAEs (early vs. later) was analyzed. However, there were no significant associations between the PFS and the number, severity or onset of irAEs.

We next evaluated the PFS based on the location of irAEs (i.e. endocrine vs. non-endocrine, or cutaneous vs. non-cutaneous, or gastrointestinal vs. non- gastrointestinal) in each group. Although there were no significant associations between the PFS and endocrine or cutaneous irAEs, the PFS was longer in patients with gastrointestinal irAEs than in those with non-gastrointestinal irAEs (gastrointestinal vs. non-gastrointestinal: NR [95\% CI: NR-NR] vs. 6.0 months [95\% CI: 2.2-9.8] $P=0.041$ ) (Fig. 4). A multivariate analysis also confirmed that only gastrointestinal irAEs were significantly associated with a longer PFS (Table 5).

\section{Discussion}

The global phase III study "CheckMate 141 clinical trials" demonstrated that nivolumab improved the prognosis in R/MHNSCC patients compared with standard therapy [1]. That study showed that the ORR was $13.3 \%$, and the 1 -year OS rate was $36.0 \%$ in patients treated with nivolumab. It also mentioned that treatment-related adverse events 

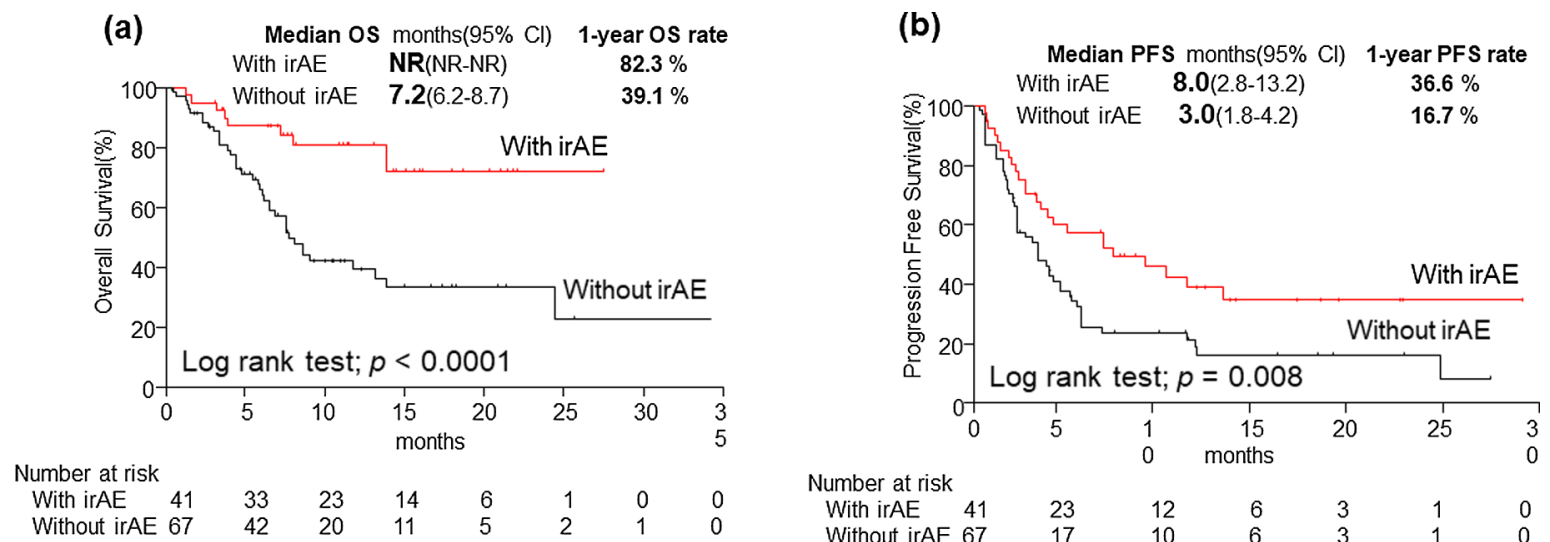

Fig. 3. Kaplan-Meier curves for the (a) overall survival (b) progression-free survival in patients with or without irAEs.

Table 4

Univariate and Multivariate analysis analyses of clinical factors associated with the OS and PFS.

\begin{tabular}{|c|c|c|c|c|c|c|c|c|}
\hline \multirow[t]{3}{*}{ Clinical factor } & \multicolumn{4}{|l|}{ PFS } & \multicolumn{4}{|l|}{ OS } \\
\hline & \multicolumn{2}{|c|}{ Univariate analysis } & \multicolumn{2}{|c|}{ Multivariate analysis } & \multicolumn{2}{|c|}{ Univariate analysis } & \multicolumn{2}{|c|}{ Multivariate analysis } \\
\hline & HR $(95 \% \mathrm{CI})$ & $\mathrm{P}$ value & HR $(95 \% \mathrm{CI})$ & $P$ value & $\mathrm{HR}(95 \% \mathrm{CI})$ & $\mathrm{P}$ value & $\mathrm{HR}(95 \% \mathrm{CI})$ & $\mathrm{P}$ value \\
\hline \multicolumn{9}{|l|}{ Age } \\
\hline $\begin{array}{l}<75 \text { years }(\mathrm{n}=90) \\
\geqq 75 \text { years }(\mathrm{n}=18)\end{array}$ & $\begin{array}{l}0.73 \\
(0.35-1.36)\end{array}$ & 0.338 & $\begin{array}{l}0.42 \\
(0.17-0.91)\end{array}$ & 0.026 & $\begin{array}{l}1.42 \\
(0.64-2.80)\end{array}$ & 0.366 & $\begin{array}{l}0.85 \\
(0.33-1.96)\end{array}$ & 0.714 \\
\hline \multicolumn{9}{|l|}{ ECOG PS } \\
\hline $\begin{array}{l}0-1(\mathrm{n}=101) \\
2-4(\mathrm{n}=7)\end{array}$ & $\begin{array}{l}5.62 \\
(2.28-11.96)\end{array}$ & $\underline{0.0006}$ & $\begin{array}{l}11.67 \\
(3.95-31.80)\end{array}$ & $<0.0001$ & $\begin{array}{l}12.80 \\
(4.81-30.92)\end{array}$ & $<0.0001$ & $\begin{array}{l}11.57 \\
(3.77-33.09)\end{array}$ & $<0.0001$ \\
\hline \multicolumn{9}{|l|}{ Radiotherapy to locoregional site } \\
\hline $\begin{array}{l}\text { Radiotherapy + (n=105) } \\
\text { Radiotherapy - }(\mathrm{n}=3)\end{array}$ & $\begin{array}{l}0.68 \\
(0.25-2.80)\end{array}$ & 0.544 & $\begin{array}{l}1.46 \\
(0.52-6.10)\end{array}$ & 0.512 & $\begin{array}{l}0.28 \\
(0.10-1.15)\end{array}$ & 0.072 & $\begin{array}{l}0.60 \\
(0.21-2.57)\end{array}$ & 0.445 \\
\hline \multicolumn{9}{|l|}{ Prior systemic therapy } \\
\hline $\begin{array}{l}\text { Cetuximab containing therapy }+(n=48) \\
\text { Cetuximab containing therapy }-(n=60)\end{array}$ & $\begin{array}{l}1.39 \\
(0.89-2.19)\end{array}$ & 0.151 & $\begin{array}{l}1.56 \\
(0.97-2.51)\end{array}$ & 0.067 & $\begin{array}{l}1.30 \\
(0.73-2.32)\end{array}$ & 0.373 & $\begin{array}{l}1.46 \\
(0.79-2.75)\end{array}$ & 0.229 \\
\hline \multicolumn{9}{|l|}{ IrAEs } \\
\hline $\begin{array}{l}\text { With irAEs }(\mathrm{n}=41) \\
\text { Without irAEs }(\mathrm{n}=67)\end{array}$ & $\begin{array}{l}0.53 \\
(0.32-0.85)\end{array}$ & $\underline{0.0081}$ & $\begin{array}{l}0.53 \\
(0.31-0.86)\end{array}$ & $\underline{0.01}$ & $\begin{array}{l}0.26 \\
(0.12-0.52)\end{array}$ & $<0.0001$ & $\begin{array}{l}0.29 \\
(0.13-0.61)\end{array}$ & $\underline{0.0007}$ \\
\hline
\end{tabular}

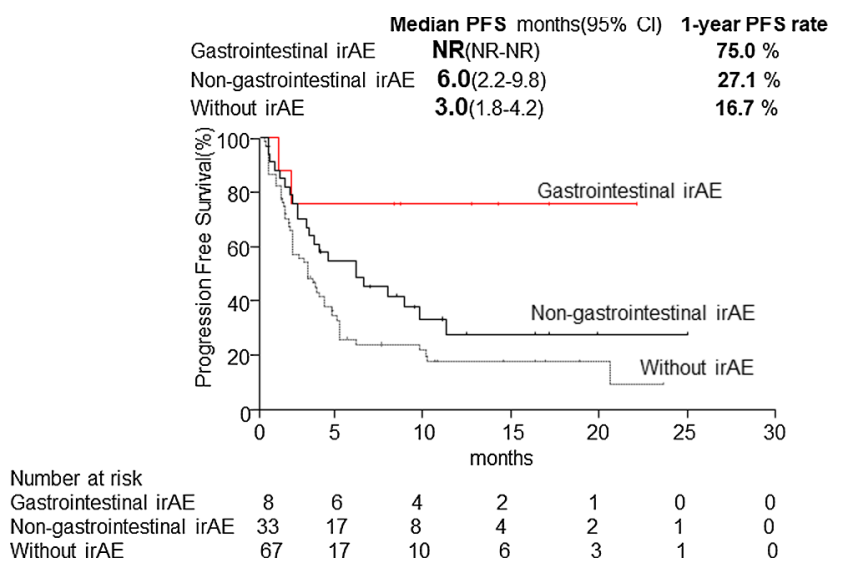

Fig. 4. Kaplan-Meier curves for the progression-free survival in patients with gastrointestinal or non-gastrointestinal irAEs or in those without irAEs at all.

occurred in $58.9 \%$ of patients (Grade $\geq 3$ in $13.1 \%$ ) [1]. In contrast, Kiyota et al. reported that the ORR and OS appeared better in the Asian population than in other populations according to the CheckMate 141 subgroup analysis when the efficacy of nivolumab in the Asian population receiving nivolumab was compared with the global results [12]. The present study indicated that the ORR was $29.6 \%$, and the 1-year OS rate was $54.4 \%$. These results were favorable compared to those of the
Table 5

Univariate and Multivariate analysis analyses of the effect of irAE development location on PFS.

\begin{tabular}{|c|c|c|c|c|}
\hline \multirow[t]{3}{*}{ location of irAEs } & \multicolumn{4}{|l|}{ PFS } \\
\hline & \multicolumn{2}{|c|}{ Univariate analysis } & \multicolumn{2}{|c|}{ Multivariate analysis } \\
\hline & HR $(95 \%$ CI) & $P$ value & HR $(95 \%$ CI) & $P$ value \\
\hline $\begin{array}{l}\text { Endocrine }(\mathrm{n}=14) \\
\quad \text { Non-endocrine }(\mathrm{n}=27)\end{array}$ & $\begin{array}{l}0.72 \\
(0.35-1.44)\end{array}$ & 0.353 & $\begin{array}{l}0.56 \\
(0.35-1.47)\end{array}$ & 0.369 \\
\hline $\begin{array}{l}\text { Cutaneous }(\mathrm{n}=11) \\
\quad \text { Non-cutaneous }(\mathrm{n}=30)\end{array}$ & $\begin{array}{l}0.61 \\
(0.27-1.41)\end{array}$ & 0.249 & $\begin{array}{l}0.65 \\
(0.28-1.52)\end{array}$ & 0.319 \\
\hline $\begin{array}{l}\text { Gastrointestinal }(\mathrm{n}=8) \\
\quad \text { Non-gastrointestinal } \\
(\mathrm{n}=33)\end{array}$ & $\begin{array}{l}0.23 \\
(0.06-0.92)\end{array}$ & $\underline{0.038}$ & $\begin{array}{l}0.23 \\
(0.06-0.94)\end{array}$ & $\underline{0.040}$ \\
\hline
\end{tabular}

"CheckMate 141 clinical trials" and consistent with the Asian subgroup analysis. These observations suggest that nivolumab may be effective for HNSCC in the Asian population.

To date, several reports have described the groups in whom nivolumab is most effective using real-world data. In the context of a changing immune environment, previous reports showed that a high PD-L1 expression correlated with an improved efficacy of ICIs [13], and the tumor antigen release elicited by radiotherapy was considered to have led to the activation of anticancer immune responses [14,15]. It was also reported that using an anti-epidermal growth factor receptor 
(EGFR) antibody (e.g. cetuximab) may disrupt the effect of nivolumab, as the inhibition of EGFR causes the downregulation of PDL-1 expression and immune escape in cancer [16-18]. Although we could not find any correlation between the effects of nivolumab and the history of radiotherapy or cetuximab therapy in the univariate and multivariate analyses of the present study, we must consider that this interaction may occur when both treatments are administered concurrently. In fact, multiple ongoing clinical trials are investigating the combination of anti-PD1 antibodies with chemoradiotherapy (NCT02952586, NCT3040999, NCT02999087, NCT03349710, NCT03258554), and the combination of anti-PD1 inhibitors with cetuximab and RT (NCT03258554) [19].

Our findings showed that the patients with irAEs had a significantly higher ORR and a longer PFS and OS than those without irAEs, and the development of irAEs was associated with a survival benefit in patients with R/MSCC treated with nivolumab. Our results were consistent with those of previous studies of malignant tumors, including head and neck cancer [20], lung cancer [5,6], melanoma [7], and renal cell cancer [8].

Adverse events of antitumor agents usually progress to dose-limiting toxicities or result in the interruption of antitumor therapy, so patients who show such side effects generally have a poor prognosis. In contrast, the irAEs of ICIs typically indicate an encouraging response and a clinical benefit for the treated patients. It has been suggested that tumor neoantigens and normal tissue antigens might cross-react in the patients with irAEs and this active immune status may have been the cause of the meaningful outcome obtained in our study [21].

Regarding the pattern and type of irAEs, although previous reports have indicated that the development of multiple irAEs [5], an early irAE onset (within two week) [11] or a severe grade $(\geq 3)$ [9] are associated with the clinical outcome, we found no evidence supporting any of these associations. In contrast, our multivariable analysis showed that only gastrointestinal irAEs were significantly associated with a longer PFS. Several reports have shown that a longer PFS or OS after treatment with ICIs is associated with irAEs in specific organs, and the occurrence of specific irAEs might depend on the type of cancer $[5,7,8,10,22]$. For example, the occurrence of cutaneous irAEs only correlated with a better outcome in melanoma patients [7], whereas gastrointestinal and endocrine irAEs had a statistically significant association with a longer PFS in lung cancer patients [5]. The mechanism underlying this correlation is not well understood. However, these findings suggest that cancer cells and the tissues in which irAEs occur are very similar in makeup [5], or the modulation of the PD-1 pathway may cause typical cutaneous changes similar to graft-versus-host-disease (GVHD) [23,24]. As the skin and gastrointestinal tract are the organs that develop GVHD most frequently, if we consider irAEs to indicate an excessive immunoreaction, then cutaneous and/or gastrointestinal irAEs may be associated with a good prognosis.

Several limitations are associated with this study, including its retrospective nature, small sample size and insufficient examination of the PD-L1 expression. Given these limitations, we intend to accumulate a larger number of R/MHNSCC patients and their associated data over a long follow-up period. We believe that the present investigation is a useful stepping stone for our next study, with further confirmation of our findings warranted.

\section{Conclusion}

In conclusion, the major finding of this study is suggested to be that unique immune toxicities, commonly described as irAEs, are significantly associated with improved treatment outcomes, including the survival, and tumor response in R/MHNSCC patients receiving nivolumab therapy. We believe that the development of irAEs may aid in the earlier prediction of an anticancer effect in patients with recurrent or metastatic HNSCC during nivolumab monotherapy.

\section{Declaration of Competing Interest}

The authors declare that they have no known competing financial in-terests or personal relationships that could have appeared to influence the work reported in this paper.

\section{Acknowledgements}

We have no disclosures and received no financial support in association with this study.

\section{References}

[1] Ferris RL, Blumenschein Jr G, Fayette J, Guigay J, Colevas AD, Licitra L, et al. Nivolumab for recurrent squamous-cell carcinoma of the head and neck. N Engl J Med 2016;375:1856-67.

[2] Wang Q, Gao J, Wu X. Pseudoprogression and hyperprogression after checkpoint blockade. Int Immunopharmacol 2018;58:125-35.

[3] Carbone DP, Reck M, Paz-Ares L, Creelan B, Horn L, Steins M, et al. First-line nivolumab in stage IV or recurrent non-small-cell lung cancer. N Engl J Med 2017;376:2415-26

[4] Michot LM, Bigenwald C, Champiat S, Collins M, Carbonnel F, Postel-Vinay S, et al. Immune-related adverse events with immune checkpoint blockade: a comprehensive review. Eur J Cancer 2016;54:139-48.

[5] Ricciuti B, Genova C, Giglio AD, Bassanelli M, Dal Bello MG, Metro G, et al. Impact of immune-related adverse events on survival in patients with advanced non-small cell lung cancer treated with nivolumab: long-term outcomes from a multi-institutional analysis. J Cancer Res Clin Oncol 2019;145:479-85.

[6] Haratani K, Hayashi H, Chiba Y, Kudo K, Yonesaka K, Kato R, et al. Association of immune-related adverse events with nivolumab efficacy in non-small-cell lung Cancer. JAMA Oncol 2018;4:374-8.

[7] Freeman-Keller M, Kim Y, Cronin H, Richards A, Gibney G, Weber JS. Nivolumab in resected and unresectable metastatic melanoma: characteristics of immune-related adverse events and association with outcomes. Clin Cancer Res 2016;15(22):886-94.

[8] Ishihara H, Takagi T, Kondo T, Homma C, Tachibana H, Fukuda H, et al. Association between immune-related adverse events and prognosis in patients with metastatic renal cell carcinoma treated with nivolumab. Urol Oncol 2019;37(355):e21-9.

[9] Fujii T, Colen RR, Bilen MA, Hess KR, Hajjar J, Suarez-Almazor ME, et al. Incidence of immune-related adverse events and its association with treatment outcomes: the MD Anderson Cancer Center experience. Invest New Drugs 2018;36:638-46.

[10] Teulings HE, Limpens J, Jansen SN, Zwinderman AH, Reitsma JB, Spuls PI, et al. Vitiligo-like depigmentation in patients with stage III-IV melanoma receiving immunotherapy and its association with survival: a systematic review and metaanalysis. J Clin Oncol 2015;33:773-81.

[11] Teraoka S, Fujimoto D, Morimoto T, Kawachi H, Ito M, Sato Y, et al. Early immunerelated adverse events and association with outcome in advanced non-small cell lung cancer patients treated with nivolumab: a prospective cohort study. J Thorac Oncol 2017; 12:1798-805.

[12] Kiyota N, Hasegawa Y, Takahashi S, Yokota T, Yen CJ, Iwae S, et al. A randomized, open-label, Phase III clinical trial of nivolumab vs. therapy of investigator's choice in recurrent squamous cell carcinoma of the head and neck: a subanalysis of Asian patients versus the global population in checkmate 141. Oral Oncol 2017:73:138-46.

[13] Garon EB, Rizvi NA, Hui R, Leighl N, Balmanoukian AS, Eder JP, et al. Pembrolizumab for the treatment of non-small-cell lung cancer. N Engl J Med 2015;372:2018-28.

[14] Levy A, Chargari C, Marabelle A, Perfettini JL, Magné N, Deutsch E. Can immunostimulatory agents enhance the abscopal effect of radiotherapy? Eur J Cancer 2016;62:36-45.

[15] Postow MA, Callahan MK, Barker CA, Yamada Y, Yuan J, Kitano S, et al. Immunologic correlates of the abscopal effect in a patient with melanoma. $\mathrm{N}$ Engl $\mathrm{J}$ Med 2012;366:925-31.

[16] Lee CK, Man J, Lord S, Links M, Gebski V, Mok T, et al. Checkpoint inhibitors in metastatic EGFR-mutated non-small cell lung cancer-a meta-analysis. J Thorac Oncol 2016;12:403-7.

[17] Gainor JF, Shaw AT, Sequist LV, Fu X, Azzoli CG, Piotrowska Z, et al. EGFR mutations and ALK rearrangements are associated with low response rates to PD-1 pathway blockade in non-small cell lung cancer (NSCLC): a retrospective analysis. Clin Cancer Res 2016;22:4585-93.

[18] Concha-Benavente F, Ferris RL. Reversing EGFR mediated immune escape by targeted monoclonal antibody therapy. Front Pharmacol 2017;8:332.

[19] Cramer JD, Burtness B, Ferris RL. Immunotherapy for head and neck cancer: Recent advances and future directions. Oral Oncol 2019;99:104460.

[20] Okamoto I, Sato H, Kondo T, Koyama N, Fushimi C, Okada T, et al. Efficacy and safety of nivolumab in 100 patients with recurrent or metastatic head and neck cancer - a retrospective multicentre study. Acta Otolaryngol 2019;139(10):918-25.

[21] Snyder A, Makarov V, Merghoub T, Yuan J, Zaretsky JM, Desrichard A, et al. Genetic basis for clinical response to CTLA-4 blockade in melanoma. N Engl J Med 2014;371:2189-99.

[22] Hasan Ali O, Diem S, Markert E, Jochum W, Kerl K, French LE, et al. Characterization of nivolumab-associated skin reactions in patients with metastatic 
non-small cell lung cancer. Oncoimmunology 2016;5:e1231292.

[23] Amarnath S, Costanzo CM, Mariotti J, Ullman JL, Telford WG, Kapoor V, et al. Regulatory T cells and human myeloid dendritic cells promote tolerance via programmed death ligand-1. PLoS Biol 2010;8:e1000302.
[24] Fujiwara H, Maeda Y, Kobayashi K, Nishimori H, Matsuoka K, Fujii N, et al. Programmed death-1 pathway in host tissues ameliorates Th17/Th1-mediated experimental chronic graft-versus-host disease. J Immunol 2014;193:2565-73. 